\title{
BEM-AVENTURAdOS OS MAUS, PORQUE POSSUIRAO A TERRA
}

\author{
Joäo Alfredo Dal Bello \\ Universidade Federal do Parand
}

\begin{abstract}
RESUMO
O presente trabalho investiga, atraves do destino da prostituta Chen Tê, o caráter parabólico da obra "A alma boa de Setsuan", de Bertolt Brecht. O autor, a partir da matéria alegórica, defende a tese de que é impossivel ao homem, nas atuais circunstâncias sociais, ser ao mesmo tempo bom e viver uma existência condigna.
\end{abstract}

\section{EM TORNO DA PARABOLA BRECHTIANA}

O nome de Bertolt Eugen Friedrich Brecht - Bert Brecht - é único entre os muitos dramaturgos épicos modernos, nāo só pela excelência e a quantidade da sua obra, mas também por ser o único a não isolar a produçäo para o palco da reflexão sobre a prática do teatro. Como dramaturgo e teórico do épico, lançou um desafio de intensa repercussão à problemática de "fazer teatro". Antes da preocupação com a forma, preconizava Brecht uma concepção teatral de caráter sócio-político. Quanto à forma, devia ser épica, oposta à dramática, que considerava ultrapassada, por induzir o espectador à condição de degustador e consumidor do que se desenrola no palco, envolvendo-o emocionalmente com a ação c os personagens, até aliená-lo da observaçāo critica e julgadora. Não se quer dizer com isto que Brecht pretendia negar ao espectador o prazer de assistir a peça teatral; desejava, antes, proporcionar-lhe um maior: o da participação produtiva, vale dizer, o prazer de julgar ativamente o que se produz no palco e de comparar tudo com a situação vigente além das paredes do teatro.

Não se entenda também que ele postulasse uma instituição moral. Seu teatro teria de ser um centro de entretenimento, que originasse, contudo, reflexão sobre fatos, e daí 
conclusões e resultados. Segundo Brecht, a forma tradicional de teatro tinha a grande desvantagem de apresentar os fatos como fixos, imutáveis, mesmo os acontecimentos históricos. $\mathrm{E}$ uma tal abordagem inculcaria no espectador a crença passiva de que tudo se repete fatalmente, sem haver quaisquer possibilidades de mudanças na dinâmica da vida e da sociedade. E claro que com um instrumento deste tipo - assim Brecht queria seu teatro de convicções marxistas - dificilmente a sociedade seria tranformada. Seu trabalho deveria ser exemplar e revolucionário. O objetivo, como ele confessa, é "nitidamente visivel, se bem que, mesmo para mim seja dificil de atingir", um mundo, no qual o "homem preste auxílio ao homem". Fundamentalmente se pode caracterizar o drama brechtiano como o que evidencia um conteúdo político-didático, baseado numa compreensão muito pessoal do marxismo.

A forma escolhida é a de parábola, com algumas exceções, como em Furcht und Elend des Dritten Reiches (Temor e Miséria do Terceiro Reich), por apresentar pormenores de uma realidade que escapariam à generalização própria da parábola. Se "parábola é uma comparação alegórica, na qual o conjunto de elementos evoca, por comparação, outras realidades de ordem superior"2, e se teatro tem de agir pedagogicamente sobre o espectador, levando-o a uma revisão crítica da sua posição face à realidade política e social, o método brechtiano de fazer teatro se justifica.

Segundo W. Hink, são três os pressupostos básicos da parábola brechtiana: 1) confiança na capacidade de aprendizagem do espectador; 2) convicção da compreensibilidade do mundo; 3) confiança na capacidade de transformação, ou como diz Dasso Saldivar, na "transformabilidad" do mundo.

Marianne Kesting divide o drama-parábola de Brecht a partir de diferentes aspectos estilísticos, que apresentam grande riqueza de variações formais, p.ex.: a peça didática de caráter realista; a parábola grotesca; a parábola de caráter oratório; parábolas biográficas, e parábolas livres que se utilizam de um exemplo histórico, legendário ou mitico ${ }^{3}$. É neste último grupo que encontramos Der gute Mensch von Sezuan (A alma boa de Setsuan)4.

Procuraremos enfocar na parábola que embasa $A$ alma boa de Setsuan o tema dialético do bem e do mal numa

1 LEISER, Erwin. O homim do não. In: - et alil. Bertolt Brecht. Bad Godersbers, Inter Nationes, 1966. p. 20.

2 FERreira, Aurélio Buarque de Holanda. Novo Dicionário da lingua portuguesa. Rio de Janeiro, Nova Fronteira, 1975. p. 1032

3 KESTING, Marianne. O teatro alemáo desde o final da segunda grerra mundial. Humboldt, (25):62-73, 1972.

4 BRECH, Bertolt. A alma boa de Setsuan. In; __ Teatro de Bertolt Brech. Rio de Janeiro, Civilizaçăo Brastleira, 1977. v.2. 
sociedade que transforma o homem, mas que também pode vir a ser transformada por ele.

\section{A ALMA BOA DE SETSUAN. Sobre a obra}

Brecht começa a escrevê-la em Berlin, retoma o trabalho, já exilado, na Suécia, na Dinamarca e na Finlândia. Somente no começo de 1941 o trabalho está concluído. Desde 0 início até este momento a peça exige-lhe aproximadamente 15 anos. O projeto inicial em Berlin, ainda sob o título Die Ware Liebe (A mercadoria Amor), surgiu no final dos anos 20 e remontava a uma ideia anterior: Fanny Kress oder der Huren einziger Freund (Fanny Kress ou $\mathrm{O}$ único amigo das Prostitutas).

O punctum saliens de $A$ alma boa de Setsuan, qual seja a temporária transformação de um homem bom em mau, causada pelo amor ao próximo e solidariedade com os companheiros de infortúnio, jả se encontra naquela primeira concepção. Na verdade, uma longa gênese. Passo a passo a matéria vai tomando contornos, até chegar à forma final, como a conhecemos. Permanece, contudo, se compararmos a concepção inicial com o trabalho concluído, a tese de que a pessoa que é ou quer ser boa está por isto mesmo condenada a fracassar. Fanny Kress intenta, transformada em homem, fugir do ambiente da prostituição. Fracassa, entretanto, porque suas companheiras, a quem também pretende ajudar, cuidam exclusivamente de seus interesses individuais, pondo todo o plano a perder.

A alma boa de Setsuan trata, basicamente, como em Die sieben Todsünden (Os sete pecados mortais), da auto-alienação do homem. Seu argumento e sua análise cênica se resumem ao seguinte:

Très deuses visitam a provincia de Setsuan, com a missão de encontrar, se ainda possivel, homens bons, pois "há dois mil anos se escuta o mesmo clamor: "O mundo não pode continuar como estä, ninguém consegue permanecer bom". Se logrado o intento e constatado que ainda há um número satisfatório de pessoas que levam uma existência condigna, poderã entāo o mundo continuar como está, por não ser mau de todo. Tematicamente a parábola remete à visita dos dois anjos a Sodoma e Gomorra, ou aos hóspedes de Filemon e Baucis.

Já de inicio parece estar o experimento dos deuses fadado a malograr, pois nem sequer alojamento para a noite lhes é concedido. Em Setsuan até os pobres e oprimidos se caracterizam pela mesma indiferença e egoismo dos seus opressores. São todos eles, grandes e pequenos, um catálogo vivo de 
"virtudes às avessas": mentirosos, ladrões, parasitas... Diante desse quadro de desregramentos parece terem os douses perdido tempo e esperanças. Uma prostituta, Chen Tê, todavia, abrirido mão do cliente que lhe traria o dinheiro necessário para o aluguel vencido, dispōe-se a hospedar os clcises. Nela encontraram os deuses a alma boa que procuram. iva manhã seguinte, ao se despedir, recompensam-na, ainda rue com ceita relutância, por não convir a deuses o envolvimento em questōes econômicas, com "mais de mil dólares de prata", com os quais Chen Tê, dias após, adquire uma pequena tabacaria. De posse desta, espera "agora poder fazer 0 bem a muita gente". E, por praticar a caridade, começa a ser explorada pelos seus próprios beneficiados: a sra. Chin, antiga proprietária da tabacaria, que já a lograra na venda, extorque-lhe agora arroz para si e sua família; uma familia de oito pessoas, um marceneiro, um aviador desempregado e sua mãe exigem de Chen Tê comida e teto. Em pouco tempo o "anjo dos subúrbios" está exposto à bancarrota. "Eles são maus, não são amigos de ninguém, brigam por uma tigela de arroz, só pensam em si mesmos: quem é que pode ficar zangado com eles?"

E nesta hora de crise que surge o primo Chui Tá. Chui Tá é, por assim dizer, o outro lado de Chen Tê, ou seja: para poder sobreviver, a alma boa tem de se tornar má. Assim, a bondosa Chen Tê se converte no desalmado Chui Tá, que leva os negócios a florirem, mesmo que para tanto tenha de explorar e entregar à policia os protegidos de sua "prima". Portanto, o que ela constrói como Chen Tê, destrói como Chui Tá. A metamorfose ocorre no meio da peça. Com a máscara e o termo do "primo" nas māos, Chen Tê comenta a situação. Cantando a "Canção da impotência dos deuses e dos bons", assume com as roupas também o caráter do mau.

O desaparecimento do anjo dos pobres, porém, causa suspeitas e, como tarda seu regresso da viagem inventada pelo "primo", crescem boatos de que este a teria assassinado para apossar-se dos negócios. Levado ao tribunal, que é presidido pelos deuses, o réu confessa sua dupla existência:

"Pois sou eu mesma: Chui Tá e Chen Tê!

A vossa antiga recomendação de ser boa e viver conforme o bem me dividiu em duas, como um raio...

Eu nem sei como foi que aconteceu: ser boa para mim e para os outros, ao mesmo tempo, não era possivel.

Era demais, servir a mim e aos outros.

Como é difícil este vosso mundo! 
A fome é tanta, é tanto o sofrimento!

A mão, que se quer estender a um pobre, ele tenta arrancar de uma vez só!

Quem procura ajudar a um desgraçado, acaba se desgraçando também!

Quem é que pode resistir assim à tentação de ser tambèm ruim, se, para nāo morrer, a carne alheia se tem de comer?

"Alguma coisa deve estar errada em vosso mundo: por que é que o mal é premiado e o bem não ganha nada, quando por sorte não é castigado?"

Impotentes diante do dilema do bom, que para sobreviver é coagido a se tornar mau, e da inutilidade dos seus mandamentos, os deuses, após recomendar mais uma vez a Chen Tê que seja razoavelmente boa e que tudo se arranjará, optam por desaparecer, levados por uma nuvem côr-de-rosa. Sorrindo e abanando para a desesperada Chen Tê, afastam-se dela, indiferentes. Cai o pano.

No epilogo um dos atores vem à ribalta apresentar pedido de desculpas ao público.

" $E$ agora, püblico amigo, não nos interprete mal: sabemos que este não foi um excelente final!

Nós fazíamos idéia de uma lenda de ouro e ela, disfarçadamente, assumiu um tom de agouro.

Ficamos tristes também ao notar, por nosso lado, tanto problema em aberto e o pano de boca fechado.

Qualquer sugestão, portanto, acatamos com respeito: recolham-se às suas casas e disto tirem proveito!

Nāo poderiamos ter maior mảgoa em confessar o nosso próprio fracasso, se alguém não nos ajudar. Talvez nada nos ocorra, agora, de puro medo: isso acontece! Entretanto, como encerrar este enredo? Já batemos o bestunto e nada achamos no fundo: se fossem outros os homens, ou se outro fosse 0 mundo, ou se os Deuses fossem outros ou nenhum - como seria?

Nós é que ficamos mal, sem nenhuma fantasia! Para esse horrivel impasse a soluçāo no momento talvez fosse vocês mesmos darem trato ao pensamento até descobrir-se um jeito pelo qual pudesse a gente ajudar uma alma boa a acabar decentemente... 
Prezado público, vamos: busquem sem esmorecer! Deve haver uma saída: precisa haver, tem que haver!

\section{O BOM HOMEM MAU E SEU MUNDO INVIAVVEL}

A peça se alterna em dez cenas longas e curtas. As cenas curtas têm o propósito de comentar e discutir a ação; nas longas é tratado o problema do bem e do mal. Na dialética bem/mal dois fatores se mostram responsáveis pelo determinismo de se ter de ser mau: a sociedade como tal e a propria natureza humana.

É impossivel ser bom em Setsuan. Os deuses acreditam ter encontrado uma alma boa $e$ aconselham-na a perseverar assim (deve-se observar que eles não reprovam a conduta moral de Chen Tê). Mas, enquanto deuses, não precisam suar pelo pão de cada dia e desconhecem, portanto, o peso da injunção que fazem a Chen Tê. $O$ primeiro entrave para o aspirante à bondade é, pois, de caráter econômico: o bom tem de esvaziar o bolso para encher o estômago do próximo, reduzindo seu próprio estômago ao estado do bolso.

Os deuses não se modificam nem evoluem no decorrer da ação. Tanto no início, como no fim, sua mensagem permanece inalterada: "seja boa e tudo se arranjará!" Se é correto afirmar com Brecht que "só o morto permanece impassivel diante de boas razões", por esta mesma razão, pode-se dizer que os deuses não são mais do que uma farsa de si mesmos, ou então um produto da concepção ingênua e da falsa consciência que Chen Tê tem de sua própria condição social e econômica. Brecht insere a presença dos deuses na peça como um elemento artificial, até descartável, sem significação substancial. Não são eles bons ou maus, nem podem exigir bondade ou castigar a maldade. $\mathrm{E}$, ao se desvanecer numa nuvem rósea, deixam claro ser ficticia a sua existência e, por extensão, inócuos os seus mandamentos.

Que dizer, então, da bondade de Chen Tê? Seria a bondade reprovável?

Como todas as personagens de Brecht, Chen Tê é um tipo governado por uma tendência, por um impulso quase mecânico que determina suas ações. "Ela não pode dizer não!" Isto quer dizer que a sua bondade não decorre de uma decisão pessoal. Não é sem razão que Di Chin e seu bando desconfiam haver outros motivos dor detrás do acentuado despreendimento do "anjo dos subúrbios".

Chen 'Tê personaliza o comportamento caritativo burguês, que se manifesta na instituição de bazares de caridade $\mathrm{e}$ iniciativas filantrópicas que, por serem paliativos, deixam 
o necessitado à espera de novo auxilio. Assim sendo, seria útil e mesmo desejável para a transformação da sociedade de Setsuan a presença e a atuação de um "anjo dos subúrbios"?

Pondo em questionamento a necessidade que Chen Tê sente de ser boa, chega-se à advertência frequiente e insisten. te nas obras de Brecht: "Schrecklich ist die Verführung zur Güte." (Terrível é a sedução à bondade). Ele demonstra em seus dramas - e neste senticlo sāo todos eles "peças didáticas" - que a humanidade está corrompida pela violência, pelo egoismo e o individualismo.

Será certamente sufocado todo aquele que andar em sentido contrário ao da sociedade. A bondade pode, portanto, ser um mal. Numa das anedotas do Senhor Keuner, que são, como dizia Brecht, " tentativas de se fazer citáveis os gestos", o autor se expressa, como que comentando A alma boa de Setsuan, recém escrita, da seguinte forma: "O $\mathrm{Sr}$. Keuner receia que o mundo possa tornar-se inabitável quando se exigir crimes muito grandes ou virtudes muito grandes para que o homem possa garantir seu sustento. Assim o Sr. Keuner foge de um pais ao outro, pois em todos os lugares exigem demais dele, seja espirito de sacrifício, valentia, esperteza ou sede de justiça, ou, por outro lado, crueldade, etc. Todos esses países são inabitáveis." "

$\mathrm{Em}$ Mutter Courage und ihre Kinder (Mãe Coragem e seus filhos)", Kattrin, moça surda, que "tem bom coração", é assassinada ao tentar, com toques de tambor, despertar e alertar as sentinelas da cidade de que os inimigos estão por tomá-la. Tudo o que queria era poupar a vida das crianças "inocentes e que nada sabem".

$\mathrm{Na}$ sociedade entrevista por Brecht, os expoentes humanos, os que se destacam dos demais, são dispensáveis. É também de Mãe Coragem a seguinte ponderação: "Além do mais, onde há muita virtude, é sinal de que alguma coisa vai mal. ... Num país bom não há necessidade de virtudes: todos podem ser bem comuns, nem bons, nem maus, e, por mim, podem até ser covardes." Hả também na peça Das Leben des Galilei (Galileu Galilei)' uma passagem bastante expressiva a este respeito. Decepcionado com a pusilanimidade do mestre, que renega suas convicçōes diante dos ferros da Inquisição, o discípulo atira ao rosto do sábio: "Infeliz o pais q̣ue não tem heróis!" "Não," rẹlica Galileu, "antes, infeliz o pais que tem necessidade de heróis!"

5 HeCHT. Werner. Bertolt Brcchts Arbcitsjournal. Frankfurt a.M., 1973. v.3 p.48.

6 BRECH, Bertolt. Mae Corasem. In: - Teztro de Bertolt Brcch. Rlo da Janeiro. Clvillzaço uraslleirn. 1976. v.1. 
E na crítica ao caos social e na repulsa ao apelo idealista endereçado ao indivíduo que Brecht se distancia dos dramaturgos de crítica social do Expressionismo. "Para se tornar homens, os heróis devem renunciar a tudo o que fazia deles heróis (o nome, a consciência de seus feitos...) Trata-se de abdicar da própria personalidade para fundir-se na massa, para aceitar a verdade da História e poder fazê-la em seguida." "Brecht admite que, se o homem é feito e pode ser modificado pelo mundo, o mundo também é feito pelo homem, deixando-nos a tarefa de concluir que o mundo, portanto, pode ser modificado pelo homem". ${ }^{\circ}$ O oprimido é, pois, também responsável pela opressão que sofre.

O enredo dramático de $A$ alma boa de Setsuan, enquanto parábola, não teria necessariamente de ser situado numa cidađe chinesa, nem de ligar-se à situação sócio-política específica daquela sociedade. E uma situação modelo num estado modelo, num determinado momento histórico e, como tal, substitutiva-construtiva. $\mathbf{E}$ por isso mesmo que uma encenação calcada na correspondência histórica direta não corresponde à concepção do autor. É preciso reconhecer que as fábulas das peças brechtianas têm a sua localização histórica e que Brecht se torna atual pela historização. Que a exploração do homem pelo homem é constante, universal e multifacetada, evidencia com vigor a poesia Fragen eines lesenden Arbeiters (Perguntas de um operário que lê)" ${ }^{\prime}$, do mesmo Brecht: em todas as épocas e em todos os continentes (mesmo nos já submersos) os homens fracassaram coletivamente, uns por prepotência, outros por passiva submissão, na construção de um mundo habitável.

Vale para a expectativa com que o "Stuickeschreiber" o escritor de peças - concebeu seu teatro aquilo que Arnaldo Saraiva diz na apresentação de sua seleção e estudo de poemas de Brecht: "Brecht não o deixou dito, que saibamos, mas é de crer que ele gostaria que seus poemas fossem envelhecendo à medida que fôssemos entrando no seu futuro. Mas todos sabemos, ou podemos agora saber, como eles continuam "novos": atuais. Infelizmente para nós, que felizmente os temos."10

\section{ZUSAMMENFASSUNG}

Die vorliegende Arbeit untersucht an den Schicksalen des Strassenmädchens Shen Te den Parabelcharakter des

8 DORT, Bernard. O teatro e sua realidade. São Paulo, Perspectiva, 1977, p.292.

9 KESTING, Marianne. Fragen eines lesenden Arbeiters. In: - Bertolt Brecht in Selbstzeugnissen und Bilddokumenten. Hamburg, Rowohlt, 1959. p.97.

10 SaRaiva, Arnaldo. Bertolt Brecht - Poemas. Lisboa, Presença, [1976]. p.24. 
von Brecht als Parabelstück verstandenen Werks "Der gute Mensch von Sezuan".

Aus dem gleichnishaften Stoff wollte der Autor die These gewinnen, dass es dem Menschen unmöglich ist, unter den herrschenden Verhältnissen der Gesellschaft menschenwlirdig zu leben und zugleich gut zu sein. 